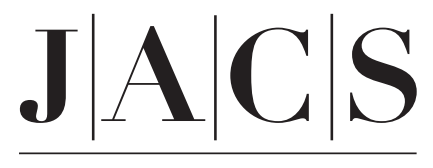

A R T I C L E S

Published on Web 10/07/2006

\title{
Probing the Intrachain and Interchain Effects on the Fluorescence Behavior of Pentiptycene-Derived Oligo( $p$-phenyleneethynylene)s
}

\author{
Jye-Shane Yang, ${ }^{*} \dagger$ Jyu-Lun Yan, ${ }^{\ddagger}$ Chung-Yu Hwang, ${ }^{\ddagger}$ Shih-Yi, Chiou, ${ }^{\ddagger}$ \\ Kang-Ling Liau,,$^{\ddagger}$ Hui-Hsu Gavin Tsai, ${ }^{\ddagger}$ Gene-Hsiang Lee, ${ }^{\dagger}$ and Shie-Ming Peng ${ }^{\dagger}$ \\ Contribution from the Department of Chemistry, National Taiwan University, Taipei, Taiwan \\ 10617, and Department of Chemistry, National Central University, Chungli, Taiwan 32054
}

Received June 21, 2006; E-mail: jsyang@ntu.edu.tw

\begin{abstract}
The synthesis, crystal structure, and fluorescence behavior of acetylene-bridged pentiptycene dimer (2), trimer (3), and tetramer (4) are reported. For comparison, a phenylene-pentiptycene-phenylene three-ring system (5) is also investigated. As a result of the unique intrachain pentiptycene-pentiptycene interactions in $\mathbf{3}$ and $\mathbf{4}$, their twisted conformers are populated in polar solvents and at low temperatures, and the phenomenon of nonequilibration of excited rotational conformers is observed. Twisting of the $\pi$-conjugated backbones leads to blue-shifted absorption and fluorescence spectra and increased fluorescence quantum yields and lifetimes. The fluorescence spectra of 2-4 undergo small red shifts but large intensity variations in the $0-1$ vs $0-0$ bands on going from solutions to thin solid films, which can be accounted for by the reabsorption effect. However, the reduction in fluorescence quantum yields for 2-4 in films vs solutions is mainly attributed to efficient interchain exciton migration to nonfluorescent energy traps. In contrast, the behavior of nonequilibration of excited rotamers is not observed for $\mathbf{5}$ in solutions. Compound 5 forms $J$-type aggregates through terminal phenylene $\pi$-stackings in the solid state, resulting in a new absorption band at $377 \mathrm{~nm}$ and large red shifts of the structured fluorescence spectra.
\end{abstract}

\section{Introduction}

The great potential of $\pi$-conjugated oligomers and polymers for application in optoelectronic devices has stimulated a great amount of theoretical ${ }^{1,2}$ and experimental ${ }^{3-12}$ research on their

National Taiwan University.

$\doteqdot$ National Central University.

(1) (a) Cornil, J.; dos Santos, D. A.; Crispin, X.; Silbey, R.; Brédas, J. L. J. Am. Chem. Soc. 1998, 120, 1289-1299. (b) Brédas, J.-L.; Cornil, J.; Beljonne, D.; dos Santos, D. A.; Shuai, Z. Acc. Chem. Res. 1999, 32, $267-$ 276. (c) Cornil, J.; dos Snatos, D. A.; Silbey, R.; Brédas, J.-L. Synth. Met. 1999, 101, 492-495. (d) Beljonne, D.; Cornil, J.; Silbey, R.; Millié, P.; Brédas, J.-L. J. Chem. Phys. 2000, 112, 4749-4758. (e) Cornil, J.; Beljonne D.; Calbert, J.-P.; Brédas, J.-L. Adv. Mater. 2001, 13, 1053-1067. (f) Brédas, J.-L.; Beljonn, D.; Coropceanu, V.; Cornil, J. Chem. Rev. 2004 104, 4971-5003.

(2) (a) Tretiak, S.; Mukamel, S. Chem. Rev. 2002, 102, 3171-3212. (b) Spano, F. C. J. Chem. Phys. 2003, 118, 981-994. (c) Brown, P. J.; Thomas, D. S.; Köhler, A.; Wilson, J. S.; Kim, J.-S. Phys. Rev. B 2003, 67, 064203. (d) Mennucci, B.; Tomasi, J.; Cammi, R. Phys. Rev. B 2004, 70, 205212. (e) Spano, F. C. Phys. Rev. B 2005, 71, 235208

(3) (a) Sartori, S. S.; De Feyter, S.; Hofkens, J.; Van der Auweraer, M.; De Schryver, F.; Brunner, K.; Hofstraat, J. W. Macromolecules 2003, 36, 500507. (b) Traiphol, R.; Sanguansat, P.; Srikhirin, T.; Kerdcharoen, T.; Osotchan, T. Macromolecules 2006, 39, 1165-1172.

(4) Jenekhe, S. A.; Osaheni, J. A. Science 1994, 265, 765-768.

(5) Spano, F. C. J. Chem. Phys. 2002, 116, 5877-5891.

(6) Donley, C. L.; Zaumseil, J.; Andreasen, J. W.; Nielsen, M. M.; Sirringhaus, H.; Friend, R. H.; Kim, J.-S. J. Am. Chem. Soc. 2005, 127, 12890-12899.

(7) (a) Leclerc, M. Adv. Mater. 1999, 11, 1491-1498. (b) McQuade, D. T.; Pullen, A. E.; Swager, T. M. Chem. Rev. 2000, 100, 2537-2574. (c) Chunwaschirasiri, W.; Tanto, B.; Huber, D. L.; Winokur, M. J. Phys. Rev. Lett. 2005, 94, 107402 .

(8) (a) Chiavarone, L.; Terlizzi, M. D.; Scamarcio, G.; Babudri, F.; Farinola, G. M.; Naso, F. Appl. Phys. Lett. 1999, 75, 2053-2055. (b) McQuade, D. T.; Kim, J.; Swager, T. M. J. Am. Chem. Soc. 2000, 122, 5885-5886. (c) Herz, L. M.; Silva, C.; Phillips, R. T.; Setayesh, S.; Müllen, K. Chem. Phys. Lett. 2001, 347, 318-324. (d) Li, L.; Collard, D. M. Macromolecules 2005, 38, 372-378.

10.1021/ja0640389 CCC: $\$ 33.50$ @ 2006 American Chemical Society solid-state photophysics. It is recognized that the luminescence properties of these $\pi$-systems in thin solid films are generally dictated by the low-energy sites due to efficient intrachain and interchain exciton migrations. The low-energy sites could be the intrachain segments of relatively long conjugation length, ${ }^{3}$ the regions of strong interchain electronic couplings (e.g., excimers and aggregates), ${ }^{4}$ structural defects, ${ }^{5}$ or even impurities, ${ }^{6}$ which in turn depends on a variety of factors such as the nature of the building blocks, ${ }^{7}$ the type and position of substituents, ${ }^{8}$ the chain length of $\pi$-conjugated backbones, ${ }^{9}$ the morphology of thin films, ${ }^{6,10}$ and the history of sample preparations. ${ }^{11}$ As a result, understanding the intrinsic intrachain conformation and interchain electronic coupling effects for the target systems is essential to address the exact nature of the emissive states. ${ }^{12}$

The intrachain vs interchain effects on the photophysical properties of poly( $p$-phenyleneethynylene)s (PPEs) in thin films or nonsolvents have received much attention. ${ }^{13-22}$ This is in

(9) Nesterov, E. E.; Zhu, Z.; Swager, T. M. J. Am. Chem. Soc. 2005, 127, 10083-10088.

(10) (a) Surin, M.; Hennebicq, E.; Ego, C.; Marsitzky, D.; Grimsdale, A. C.; Müllen, K.; Brédas, J.-L.; Lazzaroni, R.; Leclère, P. Chem. Mater. 2004 16, 994-1001. (b) Zhou, C.-Z.; Liu, T.; Lin, T.-T.; Zhan, X.-H.; Chen, Z.-K. Polymer 2005, 46, 10952-10959.

(11) Kemerink, M.; van Duren, J. K. J.; van Breemen, A. J. J. M.; Wildeman, J.; Wienk, M. M.; Blom, P. W. M.; Schoo, H. F. M.; Janssen, R. A. J. Macromolecules 2005, 38, 7784-7792.

(12) (a) Kim, J. Pure Appl. Chem. 2002, 74, 2031-2044. (b) Schwartz, B. J. Annu. Rev. Phys. Chem. 2003, 54, 141-172.

(13) (a) Bunz, U. H. F. Chem. Rev. 2000, 100, 1605-1644. (b) Zheng, J.; Swager, T. M. Adv. Polym. Sci. 2005, 177, 151-179.

J. AM. CHEM. SOC. 2006, 128, 14109-14119 • 14109 
part due to the question as to whether the intrachain planarization effect or the interchain aggregation effect is more important in accounting for the differences in electronic spectra from their dilute solutions. ${ }^{14,15}$ While many efforts have been devoted to demarcating the intrachain and the interchain effects for PPEs and its segments such as diphenylacetylene (DPA) and 1,4-bis(phenylethynyl)benzene (1), ${ }^{14-20}$ the progress has been impeded by the poor control of their conformations and thus the poor knowledge of the intrinsic intrachain conformation effect. This problem is associated with the cylindrical symmetry of the ethynyl groups, leading to a rather low barrier $(<1 \mathrm{kcal} / \mathrm{mol})$ for twisting of the phenyl rings from the coplanar geometry (e.g., 1-coplanar vs 1-twisted in eq 1) in the electronic ground state. ${ }^{16,21,22}$ Swager and co-workers adopted an elegant supramo-

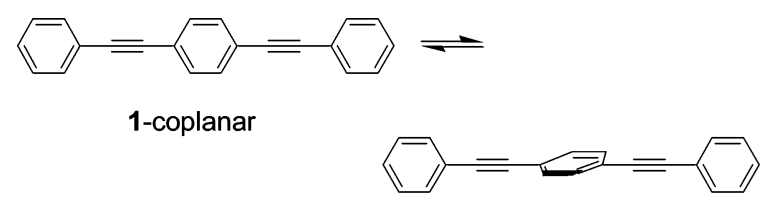

1-twisted

lecular approach to control the conformation of a series of surfactant PPEs in Lagmuir-Blodgett films. ${ }^{18}$ They observed blue-shifted fluorescence spectra and stronger fluorescence (by $38 \%$ ) for the twisted (zipper alignment) vs the coplanar (faceon alignment) forms. However, the observations might not directly reflect the intrinsic intrachain conformation effect, because interchain interactions such as the long-range dipoledipole interactions cannot be completely excluded in these monolayers, ${ }^{1}$ even though the interchain distances were calculated to be larger than $9 \AA .{ }^{18}$ Interchain dipole-dipole interactions could significantly perturb the fluorescence properties due to the induced interchain exciton migrations. This is particularly true when nonemissive traps or low-energy fluorescent sites are present. $^{5,6,19}$ It should also be noted that the efficiency of interchain exciton migrations might depend on the conformation in view of the fact that the efficiency of intrachain exciton migration in PPEs is strongly conformation-dependent. ${ }^{23}$ On the other hand, Bunz and co-workers adopted a covalent-bond approach to control the conformation of DPA in dilute solu-

(14) (a) Halkyard, C. E.; Rampey, M. E.; Kloppenburg, L.; Studer-Martinez, S. L.; Bunz, U. H. F. Macromolecules 1998, 31, 8655-8659. (b) Miteva, T.; Palmer, L.; Kloppenburg, L.; Neher, D.; Bunz, U. H. F. Macromolecules 2000, 33, 652-654. (c) Chu, Q.; Pang, Y. Macromolecules 2003, 36, 46144618. (d) Lebouch, N.; Garreau, S.; Louarn, G.; Belletête, M.; Durocher, G.; Leclerc, M. Macromolecules 2005, 38, 9631-9637.

(15) (a) Levitus, M.; Garcia-Garibay, M. A. J. Phys. Chem. A 2000, 104, 86328637. (b) Bunz, U. H. F.; Imhof, J. M.; Bly, R. K.; Bangcuyo, C. G.; Rozanski, L.; Bout, D. A. V. Macromolecules 2005, 38, 5892-5896.

(16) Levitus, M.; Schmieder, K.; Ricks, H.; Shimizu, K. D.; Bunz, U. H. F.; Garcia-Garibay, M. A. J. Am. Chem. Soc. 2001, 123, 4259-4265.

(17) (a) Levitus, M.; Zepeda, G.; Dang, H.; Godinez, C.; Khuong, T.-A. V.; Schmieder, K.; Garcia-Garibay, M. A. J. Org. Chem. 2001, 66, $3188-$ 3195. (b) Levitus, M.; Schmieder, K.; Ricks, H.; Shimizu, K. D.; Bunz, U. H. F.; Garcia-Garibay, M. A. J. Am. Chem. Soc. 2002, 124, 8181-8181. (c) Beeby, A.; Findlay, K.; Low, P. J.; Marder, T. B. J. Am. Chem. Soc. 2002, 124, 8280-8284.

(18) Kim, J.; Swager, T. M. Nature, 2001, 411, 1030-1034.

(19) Kim, J.; Levitsky, I. A. McQuade, D. T.; Swager, T. M. J. Am. Chem Soc. 2002, 124, 7710-7718.

(20) Brizius, G.; Billingsley, K.; Smith, M. D.; Bunz, U. H. F. Org. Lett. 2003, 5, 3951-3954.

(21) Greaves, S. J.; Flynn, E. L.; Futcher, E. L.; Wrede, E.; Lydon, D. P.; Low, P. J.; Rutter, S. R.; Beeby, A. J. Phys. Chem. A 2006. 110, 2114-2121.

(22) James, P. V.; Sudeep, P. K.; Suresh, C. H.; Thomas, K. G. J. Phys. Chem. A 2006. 110, 4329-4337.

(23) (a) Zhu, Z.; Swager, T. M. J. Am. Chem. Soc. 2002, 124, 9670-9671. (b) Nesterov, E. E.; Zhu, Z.; Swager, T. M. J. Am. Chem. Soc. 2005, 127, $10083-10088$. tions. ${ }^{20}$ The fluorescence spectra of these DPAs were similar, but the fluorescence quantum yield is significantly larger $(>5$ fold) for the more planar form. Regarding the inherent differences in chain lengths, conformational rigidity, and potential interchain effects between the Swager's and Bunz's systems, further studies are required to understand their discrepancies and to reach satisfactory conclusions on the intrinsic intrachain effects.

In this context, we have investigated new model systems in order to gain insights into the effects of the intrinsic intrachain conformation and the interchain dipole-dipole interactions on the fluorescence properties of PPEs. Our approach relies on short oligo( $p$-phenyleneethynylene)s (OPEs) with rigid and bulky substituents in each phenyl ring, namely, the acetylene-bridged pentiptycene dimer $\mathbf{2}$, trimer $\mathbf{3}$, and tetramer $\mathbf{4}$. We expect that these pentiptycene-derived OPEs would lead to interchain separations greater than $7 \AA$ in the solid state according to the $\mathrm{X}$-ray crystal packing modes previously observed for pentiptycene derivatives. ${ }^{24}$ Therefore, their solid-state fluorescence behavior will reflect the effect of interchain exciton couplings rather than that of interchain charge-transfer interactions. ${ }^{1,25}$ Indeed, it has been well demonstrated that incorporation of the bulky pentiptycene groups to PPEs in alternating phenylenes is sufficient to prevent excimer formation in thin films. ${ }^{26}$ However, this alternating pentiptycene-phenylene pattern will result in one or both of the terminal rings being the planar phenylene ring, at which interchain $\pi$-stacking interactions can occur. While such interactions might be unimportant for long PPEs, their effects would be significant for short OPEs. This is indeed demonstrated by the phenylene-pentiptycene-phenylene threering system 5 (vide infra). To ensure the absence of interchain $\pi$-stacking, the "all-pentiptycene" OPEs $\mathbf{2 - 4}$ are thus designed. Besides the consideration of interchain interactions, bulky substituents in PPEs can also affect the intrachain rotational energy profile, resulting in larger rotational barriers and multiple minima in the ground-state surface. ${ }^{27}$ This situation is indeed present in $\mathbf{3}$ and $\mathbf{4}$, which allows us to trap and characterize the twisted conformers in low-temperature glasses (vide infra). We report herein the synthesis, structures, and fluorescence behavior of $2-5$. Our results indicate that twisting of the $\pi$-conjugated

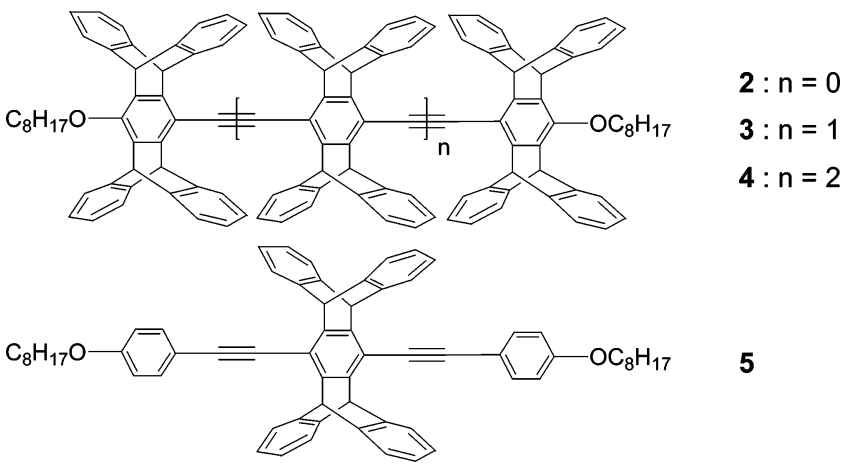

backbones in $\mathbf{3}$ and $\mathbf{4}$ results in blue-shifted fluorescence spectra and increased fluorescence quantum yields. The fluorescence

(24) (a) Yang, J.-S.; Lee, C.-C.; Yau, S.-L.; Chang, C.-C.; Lee, C.-C.; Leu, J.-M. J. Org. Chem. 2000, 65, 871-877. (b) Yang, J.-S.; Liu, C.-P.; Lee, G.-H. Tetrahedron Lett. 2000, 41, 7911-7915.

(25) Howard, I. A.; Zutterman, F.; Deroover, G.; Lamoen, D.; Van Alsenoy, C. J. Phys. Chem. B 2004, 108, 19155-19162. 



peak maxima for $\mathbf{2}-\mathbf{4}$ in the solid state resemble those in dilute solutions, but the reabsorption effects determine the relative intensity of the fluorescence vibronic bands. Both the reabsorption and interchain exciton coupling effects are associated with the order of interchain packings.

\section{Results and Discussion}

Synthesis. All the previously reported pentiptycene-incorporated PPEs belong to the pattern of alternating pentiptycenearylene copolymers derived from the palladium-catalyzed crosscoupling of pentiptycene diacetylene 6 wtih 1,4-dihaloarenes. ${ }^{26}$ "All-pentiptycene" PPEs or OPEs have not been reported, presumably due to the lack of middle-ring dihalogenated pentiptycenes such as the diiodo species $7 .^{28}$ In this context, we have carried out the synthesis of $\mathbf{2 - 4}$ through an iterative addition-aromatization method starting with the pentiptycene quinone $\mathbf{8}$.

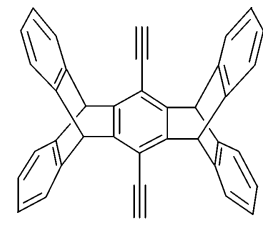

6

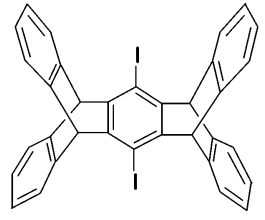

7

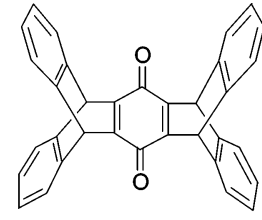

8
As shown in Scheme 1, nucleophilic addition of lithium trimethylsilylacetylide to quinone $\mathbf{8}$ followed by trapping of the phenoxide intermediate with trimethylsilyl chloride and then by reductive aromatization of the central ring produced compound $\mathbf{9}$. Compound $\mathbf{9}$ was converted to $\mathbf{1 0}$ by $O$-alkylation under a conventional $\mathrm{S}_{\mathrm{N}} 2$ reaction condition followed by deprotection of the TMS group under a basic condition. Deprotonation of the terminal alkyne in $\mathbf{1 0}$ generated a new acetylide nucleophile, which interacts with the quinone $\mathbf{8}$ to form

(26) (a) Yang, J.-S.; Swager, T. M. J. Am. Chem. Soc. 1998, 120, 5321-5322 (b) Yang, J.-S.; Swager, T. M. J. Am. Chem. Soc. 1998, 120, $11864-$ 11873. (c) Zhao, X.; Cardolaccia, T.; Farley, R. T.; Abboud, K. A.; Schanze, K. S. Inorg. Chem. 2005, 44, 2619-2627.

(27) Englert, B. C.; Smith, M. D.; Hardcastle, K. I.; Bunz, U. H. F. Macromolecules 2004, 37, 8212-8221.

(28) Yang, J.-S.; Ko, C.-W. J. Org. Chem. 2006, 71, 844-847. the pentiptycene dimer $\mathbf{2}$ through the intermediate $\mathbf{1 1}$ and the same chemistry, namely, nucleophilic carbonyl addition, reductive aromatization, and $O$-alkylation reactions.

In principle, reaction of both the carbonyl groups of $\mathbf{8}$ with the acetylides of $\mathbf{1 0}$ should lead to the trimer $\mathbf{3}$ after reductive aromatization. However, this is not the case, presumably due to steric problems. Indeed, when the less bulky trimethylsilylacetylide was used as the second equivalent of nucleophile in reacting with $\mathbf{8}$, the expected product 12 could be obtained after reductive aromatization (Scheme 2). Deprotection of the TMS group in $\mathbf{1 2}$ resulted in the dimer $\mathbf{1 3}$ with a terminal acetylene group. By following the same chemistry for the synthesis of $\mathbf{2}$ from 10, trimer $\mathbf{3}$ could be prepared from $\mathbf{1 3}$ via the intermediate 14.

An attempt to follow the same chemistry of Scheme 2 to prepare the tetramer $\mathbf{4}$ by replacing $\mathbf{1 0}$ with $\mathbf{1 3}$ as the starting material only reached a partial success. Whereas the first two steps by converting $\mathbf{1 3}$ to $\mathbf{1 5}$ and then to $\mathbf{1 6}$ were successful (Scheme 3), the subsequent nucleophilic addition and aromatization reactions have failed. The origin of this failure is unclear at present. Fortunately, we have recently accomplished the synthesis of monoiodinated pentiptycene $17,{ }^{28}$ which allowed us to prepare the tetramer $\mathbf{4}$ through the Sonogashira coupling reaction (Scheme 3). ${ }^{29}$

The three-ring system 5 was synthesized through the Sonogashira coupling reaction of $\mathbf{6}$ and 1-iodo-4-octyloxybenzene.

Molecular Structures. To investigate the iptycene substituent effects on the chain conformation of OPEs, the rotational energy surfaces for $\mathbf{3}$ and $\mathbf{5}$ in the ground $\left(\mathrm{S}_{0}\right)$ and the lowest excited state $\left(S_{1}\right)$ were calculated by maintaining the two external conjugated phenyl rings coplanar while constraining the dihedral angle $(\chi)$ formed by the central pentiptycene group to various increments of $5^{\circ}$ from the coplanar $\left(\chi=0^{\circ}\right)$ to the perpendicular $\left(\chi=90^{\circ}\right)$ form. Since the length of the terminal alkyl chains is irrelevant to this issue, the octyl groups were replaced by methyl groups in order to expedite the calculations, and the corre-

(29) Hegedus, L. S. In Organometallics in Synthesis; Schlosser, M., Ed.; John Wiley \& Sons: New York, 1994; Chapter 5. 


\section{Scheme 2}

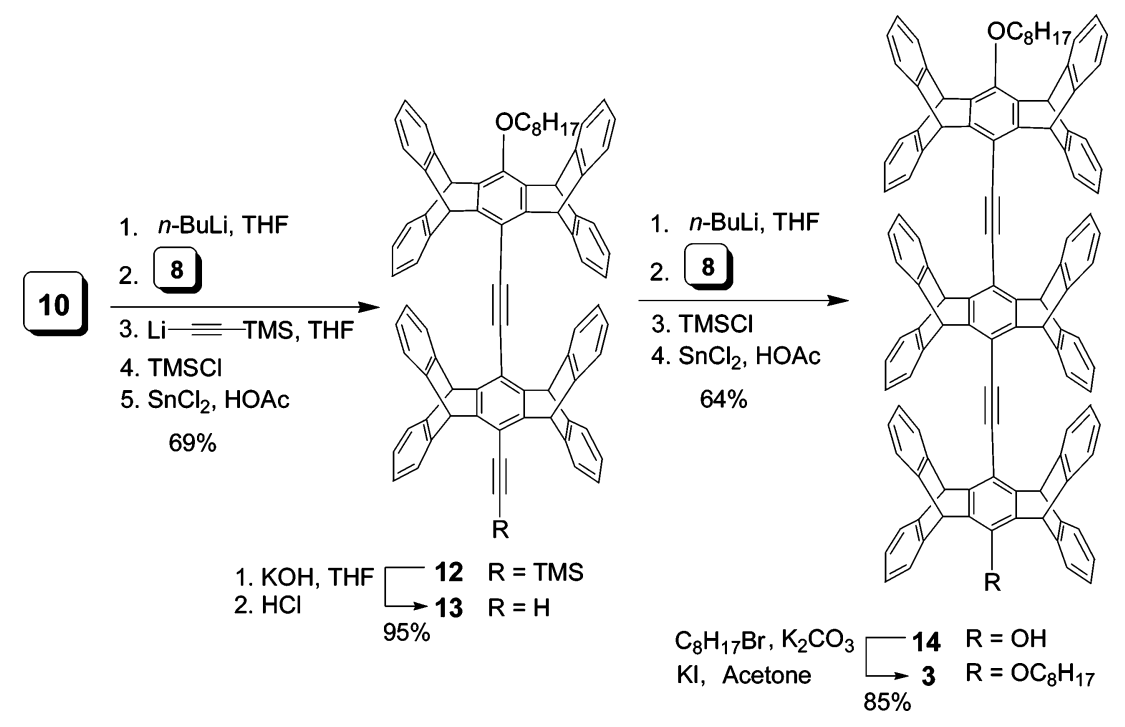

Scheme 3

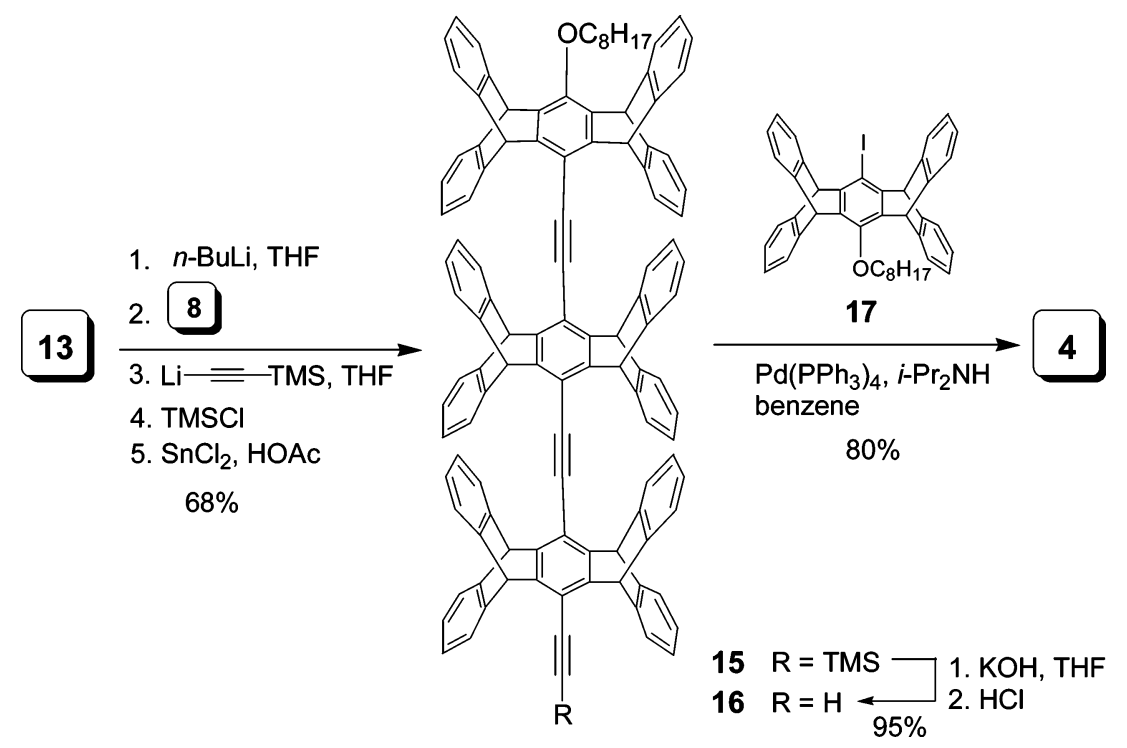

sponding compounds were named $\mathbf{3}^{\prime}$ and $\mathbf{5}^{\prime} .{ }^{30}$ The ground-state potential energy surface was determined by the AM1 algorithm. ${ }^{31}$ The excited-state rotational profile was built by adding the ZINDO-derived vertical excitation energies ${ }^{32}$ to the groundstate potential. These results are depicted in Figure 1. Because of the symmetric molecular structure, the potential energy surface for dihedral angles between $90^{\circ}$ and $180^{\circ}$ would be a mirror image of that from $0^{\circ}$ to $90^{\circ}$, and so on for further rotations. The corresponding calculations for the parent threering system 1 have previously been reported, ${ }^{16,21}$ and the rotational potential resembles that for $\mathbf{5}^{\prime}$ (Figure $1 \mathrm{~b}$ ).

The rotational profiles of $\mathbf{3}^{\prime}$ are complex when compared with those of $\mathbf{5}^{\prime}$. For example, the potential energy surface in $S_{0}$ is

(30) It should be noted that the octyl group is more electron-donating than the methyl groups, which might result in somewhat different local charges on the attached phenyl rings in $\mathbf{3}$ and $\mathbf{5}$ vs $\mathbf{3}^{\prime}$ and $\mathbf{5}^{\prime}$. However, such a difference should have negligible influence in the rotational potential due to their symmetric, linear, and nonpolar nature of the conjugated backbone. The calculated ground-state dipole moments for $\mathbf{3}^{\prime}$ and $\mathbf{5}^{\prime}$ in both their planar and twisted forms are all near $0.0 \mathrm{D}$.

(31) Dewar, M. J. S.; Zoebisch, E. G.; Healy, E. F.; Stewart, J. J. P. J. Am Chem. Soc. 1985, 107, 3902-3909.

(32) Zerner, M. C.; Leow, G. H.; Kirchner, R. F.; Mueller-Westerhoff, U. T. J. Am. Chem. Soc. 1980, 102, 589-599. essentially flat and there is only one energy minimum in $\mathrm{S}_{1}$ for $\mathbf{5}^{\prime}\left(\chi=0^{\circ}\right)$ with dihedral angles between $0^{\circ}$ and $90^{\circ}$, but for $\mathbf{3}^{\prime}$ there are three energy minima $\left(\chi=20^{\circ}, 40^{\circ}\right.$, and $\left.75^{\circ}\right)$ in $\mathrm{S}_{0}$ and two energy minima $\left(\chi=20^{\circ}\right.$ and $\left.75^{\circ}\right)$ in $S_{1}$, where the one at $\chi \approx 20^{\circ}$ possesses the lowest energy in both $\mathrm{S}_{0}$ and $\mathrm{S}_{1}$. Unlike the flat ground-state rotational potential for $\mathbf{5}^{\prime}$ (i.e., rotational barrier $=0.06 \mathrm{kcal} / \mathrm{mol}$ ), the rotational barrier for $\mathbf{3}^{\prime}$ is as high as $2.6 \mathrm{kcal} / \mathrm{mol}$ with the transition state corresponding to the coplanar form. Apparently, the bulky iptycene substituents impose substantial steric interactions between the neighboring pentiptycene groups in $\mathbf{3}^{\prime}$. A complex rotational profile calculated by AM1 has been observed for DPA with bulky substitutents. ${ }^{27}$ Despite the above differences, $\mathbf{3}^{\prime}$ and $\mathbf{5}^{\prime}$ have two things in common: (1) they possess a deeper potential energy surface in $S_{1}$ vs $S_{0}$, and (2) their vertical excitation energies increase as the dihedral angle is increased. These features predict that structural relaxation toward the conformation of $\chi \approx 20^{\circ}$ and $\chi \approx 0^{\circ}$ will occur for $\mathbf{3}^{\prime}$ and $\mathbf{5}^{\prime}$, respectively, in $\mathrm{S}_{1}$ if their excited-state lifetimes are sufficiently long and the rotational energy barrier between the energy minima in the former case is low; however, if excited-state structural relaxation is minimal, 


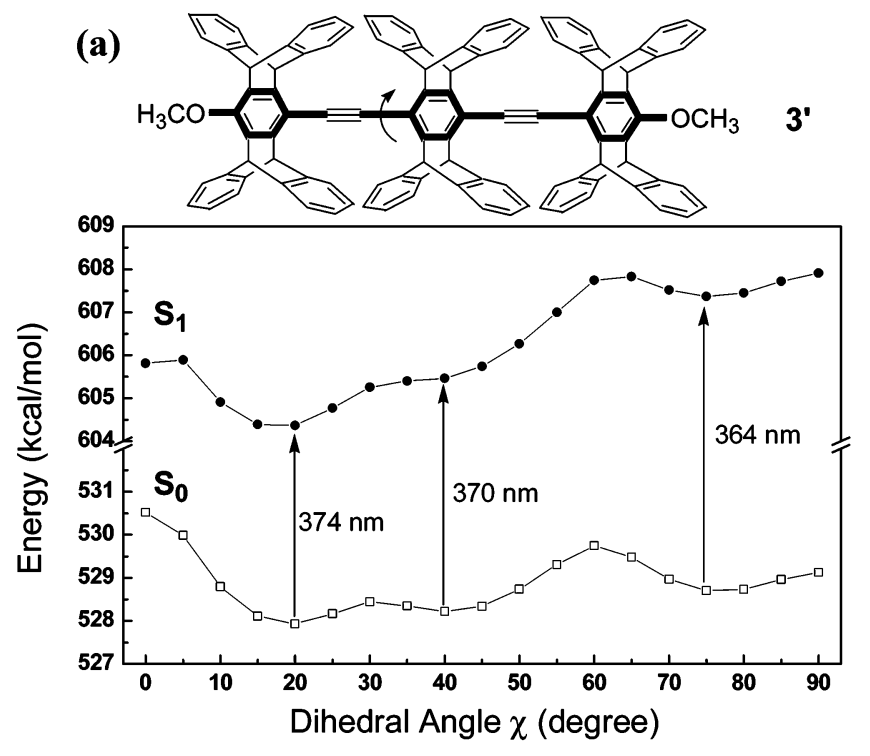

(b)

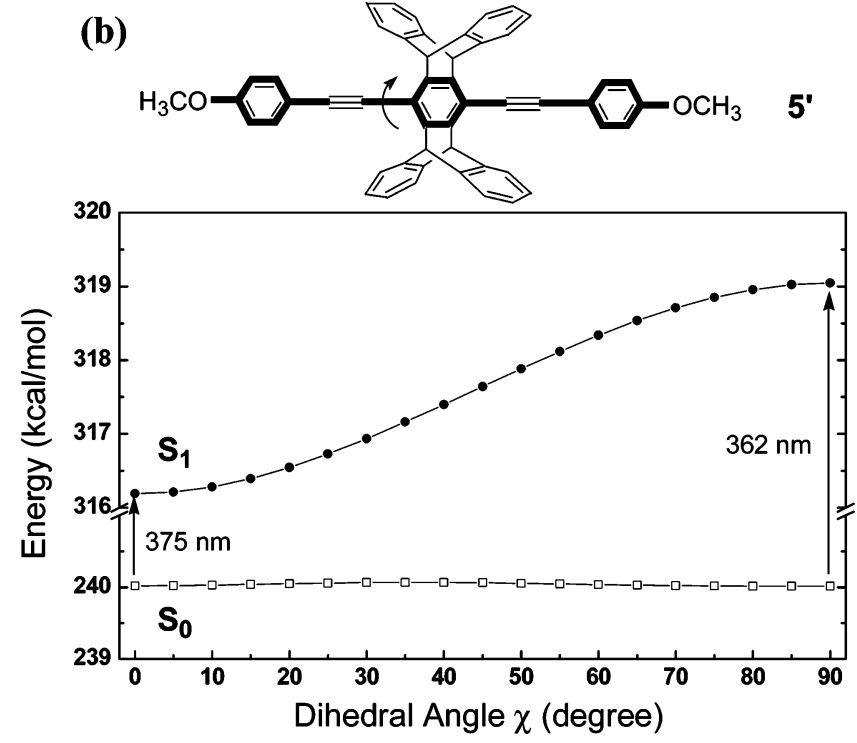

Figure 1. Rotational potential of (a) $\mathbf{3}^{\prime}$ and (b) $\mathbf{5}^{\prime}$ in the ground state (AM1) and in the first excited state. Transition energies were calculated with the ZINDO algorithm. Wavelengths for vertical transitions at selected dihedral angles are indicated with labeled arrows.

the more planar form would absorb and emit at longer wavelengths for both cases. According to the photophysical data (vide infra), the process of excited-state backbone planarization is indeed efficient for both $\mathbf{3}$ and $\mathbf{5}$ in solutions at room temperature, but this process is inhibited for $\mathbf{3}$ but not for $\mathbf{5}$ in low-temperature glasses.

Among 2-5 and the pentiptycene-derived intermediates 1116, only the dimeric intermediate $\mathbf{1 1}$ and the trimer $\mathbf{5}$ formed single crystals suitable for X-ray crystallography. As shown in Figure $2 \mathrm{a}$, the conjugated backbone in $\mathbf{1 1}$ is not coplanar, and the dihedral angle between the two phenylene rings is $35^{\circ}$. All the molecules in the crystal are aligned in the same direction (i.e., along with the $b$ axis), although the neighboring chains tilted in a head (OH)-to-tail (OR) manner (Figure 2b). In addition, the neighboring chains are longitudinally translated so that interchain pentiptycene-pentiptycene contacts are present only for the alkoxy substituted ones. The averaged interchain distance calculated from the nearest pentiptycene pairs is ca. $8 \AA$, which is similar to the ring-ring distance previously

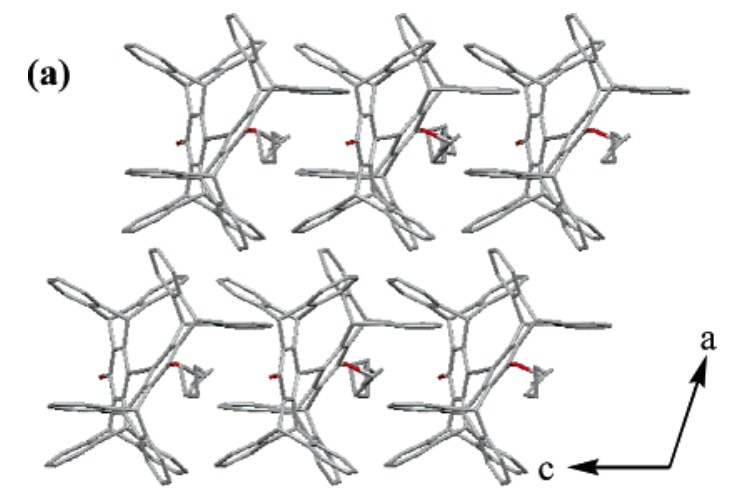

(b)

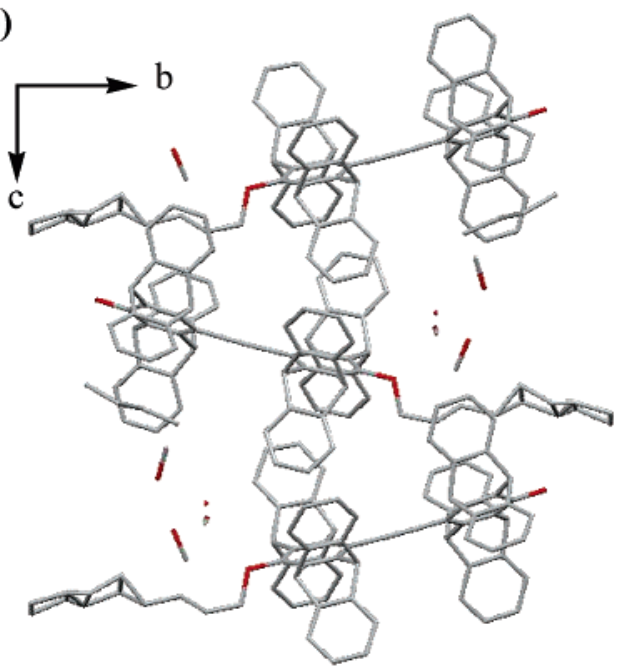

Figure 2. Crystal structures of 11: (a) crystal packing looking down the long molecular axis ( $b$ axis) showing the nonplanar conjugated backbones and layered packing motif, and (b) alignment of neighboring chains in one layer showing the head-to-tail tilted packing, included solvent molecules, and disordered octyl chains.

observed for interdigitated packing of pentiptycene derivatives. ${ }^{24}$ It is expected that the interchain alignment would be less tilted for the symmetric oligomers $\mathbf{2}-\mathbf{4}$ in order to accommodate the other octyl chain, and their interchain distances would be also about or larger than $8 \AA$. As a result, interchain $\pi$-orbital overlapping is negligible. The prevention of close intermolecular packing for $\mathbf{1 1}$ in the solid state due to the bulky pentiptycene groups is also evidenced by the presence of void space, where six molecules of methanol and two molecules of water are present in each unit cell. The loose interchain packing is also responsible for the disorder of the octyl chains. In contrast to the case of 11, the conjugated backbone in $\mathbf{5}$ is nearly coplanar in the solid state, and each molecule is $\pi$-stacked parallel with two adjacent molecules through the terminal phenylene rings with a ring-ring distance of $3.46 \AA$ (Figure 3). No solvent molecules are included in the crystal, and no disorder is found for the octyl groups. Strong interchain electronic interactions are thus expected for $\mathbf{5}$ in the solid state.

Intrachain Effects. In principle, the intrinsic intrachain conformation effect on the fluorescence of PPEs is better investigated in dilute solutions or low-temperature solvent glasses due to the negligible intermolecular interactions. However, previous works on unconstrained PPEs or its model compounds in these conditions did not provide much information about the fluorescence behavior of the twisted conformers. 

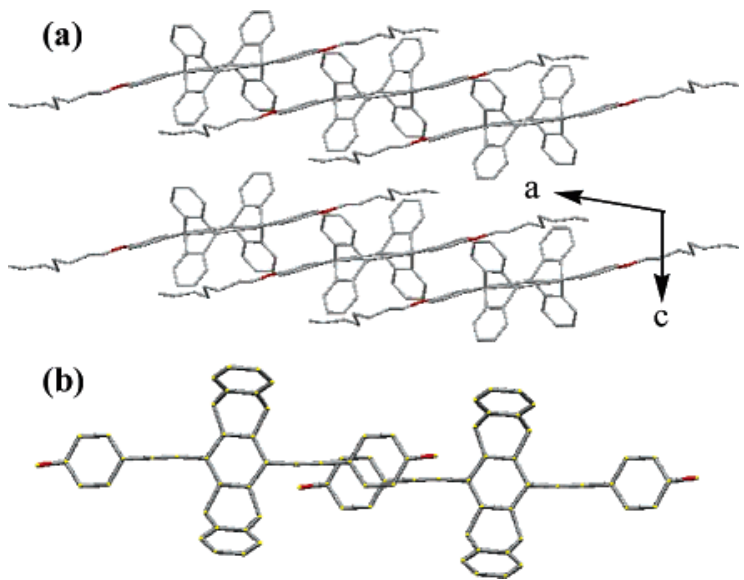

Figure 3. Crystal structure of $\mathbf{5}$ showing (a) the coplanar conjugated backbones and parallel interchain alignments and (b) interchain offset $\pi$-stacking of the terminal phenylene rings (the octyl groups were removed for clarity).

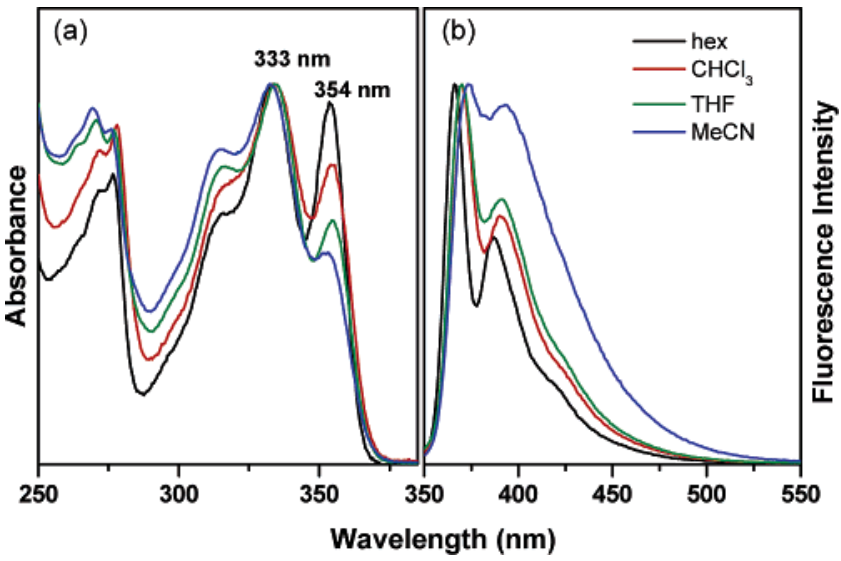

Figure 4. The (a) absorption and (b) fluorescence spectra of $\mathbf{3}$ in hexane (hex), chloroform $\left(\mathrm{CHCl}_{3}\right)$, THF, and acetonitrile $(\mathrm{MeCN})$.

For one reason, PPEs in solutions generally undergo fast excitedstate conformational relaxation to planarize the conjugated backbone before the fluorescence is emitted. ${ }^{33}$ As a result, information about the fluorescence properties of the twisted forms is lost. Although in some cases the solvent glasses can trap the nonplanar rotational conformers in the ground and the excited state, the fluorescence spectrum is either broadened with a shape like the mirror image of the corresponding absorption spectra $^{33}$ or dominated by the planar form. ${ }^{17,22}$ The former situation is a result of a continuum distribution of conformers so that spectral deconvolution is impossible. In the following, we will show that the rotational conformer distribution in $\mathbf{3}$ and 4 is narrower and shows distinct domains at different twisted angles. The equilibrium of the confomers highly depends on the solvent polarity, where the more twisted conformers are more favorable in more polar solvents or at lower temperatures. Furthermore, the excited-state rotational energy barrier between the conformers appears to be sufficiently high so that the photophysics of the twisted form can be characterized at low temperatures. We will first discuss the case of $\mathbf{3}$ and then compare it with those of $\mathbf{2}, \mathbf{4}$, and $\mathbf{5}$.

Figure 4 shows the normalized absorption and fluorescence spectra of $\mathbf{3}$ in hexane, chloroform, THF, and acetonitrile. Both

(33) Sluch, M. I.; Godt, A.; Bunz, U. H. F.; Berg, M. A. J. Am. Chem. Soc. 2001, 123, 6447-6448.

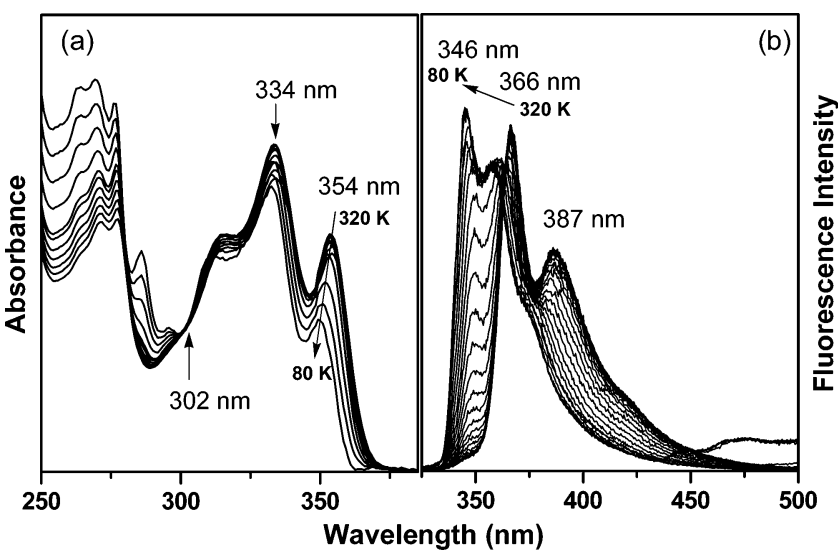

Figure 5. Temperature dependence of (a) absorption and (b) fluorescence spectra $\left(\lambda_{\mathrm{ex}}=302 \mathrm{~nm}\right)$ for 3 in MTHF at 20 - and $10-\mathrm{K}$ intervals, respectively, between 80 and $320 \mathrm{~K}$.

the absorption and fluorescence spectra in hexane show vibronic structures, and they are approximately mirror-imaged to one another, indicating a similar distribution of vibrational levels in $S_{0}$ and $S_{1}$. As the solvent polarity increases (i.e., acetonitrile $>$ THF $>$ chloroform $>$ hexane), the intensity of the 314-nm absorption shoulder increases at the expense of the 354-nm absorption band intensity. The accompanying changes in the fluorescence spectra are spectral broadening and increased intensity ratio for the $0-1$ vs the $0-0$ band $\left(I_{01} / I_{00}\right)$. Since twisting of the $\pi$-conjugated backbone is predicted to increase the electronic transition energy (Figure 1), the above observations indicate that the ground-state conformer distribution is solvent-dependent and the equilibrium shifts toward the more twisted conformers in more polar solvents. The absence of blue shifts in the fluorescence spectra is a consequence of fast backbone planarization in the excited state. ${ }^{33}$

The processes of excited-state backbone planarization can be minimized for $\mathbf{3}$ at low temperatures. Figure 5 shows the absorption and fluorescence spectra of $\mathbf{3}$ in 2-methyltetrahydrofuran (MTHF) recorded at intervals of 20 and $10 \mathrm{~K}$, respectively, between 80 and $320 \mathrm{~K}$. The absorption spectra are blue-shifted by $4 \mathrm{~nm}$ in the $0-0$ band upon lowering the temperature from 320 to $80 \mathrm{~K}$. An isosbestic point at $302 \mathrm{~nm}$ can be observed. The corresponding fluorescence spectra upon excitation at $302 \mathrm{~nm}$ also shift toward the blue by ca. $20 \mathrm{~nm}$ from 280 to $130 \mathrm{~K}$. The fluorescence spectra recorded between 280 and $320 \mathrm{~K}$ are essentially the same, and so are the spectra between 80 and $130 \mathrm{~K}$. It should be noted that weak phosphorescence is present at wavelengths larger than $440 \mathrm{~nm}$ when the temperature is lower than $110 \mathrm{~K}$. Thus, intersystem crossing is an important decay process for the excited singlet state of $\mathbf{3}$. More importantly, there also exists an isosbestic point $(363 \mathrm{~nm})$ in the fluorescence spectra as a function of temperature. These results clearly indicate the presence of two interconvertible emitting states and their interconversions are temperaturedependent (i.e., there exists an equilibrium barrier). In addition, to observe such an isosbestic point requires the absence of any activated nonradiative decay processes for both emitting states. In other words, the fluorescence quantum yield $\left(\Phi_{\mathrm{fl}}\right)$ should be temperature-independent. This is true for the parent three-ring system 1 at temperatures lower than ambient temperature. ${ }^{34}$

(34) Birckner, E.; Grummt, U.-W.; Göller, A. H.; Pautzsch, T.; Egbe, D. A. M.; Al-Higari, M.; Klemm, E. J. Phys. Chem. A 2001, 105, 10307-10315. 
Indeed, fluorescence decay analysis for data collected in the range $80-160 \mathrm{~K}$ show two temperature-independent fluorescence lifetimes, 5.6 and $0.8 \mathrm{~ns}$, corresponding to the short- and the long-wavelength emitting states, respectively. We ascribe these two states to conformers of larger and smaller twist angles in the $\pi$-conjugated backbones, respectively, but the exact dihedral angles are uncertain. According to the calculated excited-state rotational energy profile shown in Figure 1, the dihedral angles of these two emitting states might correspond to the two minima at $\chi=20^{\circ}$ and $\chi=75^{\circ}$. To simplify the following discussion, we refer to the short- and the longwavelength states as the twisted and the planar form, respectively.

Since the presence of an isosbestic point establishes the oneto-one conversion from the planar form to the twisted form, the similar integrated fluorescence peak area at 320 and $80 \mathrm{~K}$ (planar:twisted $=1: 1.06$ ) indicates that the fluorescence quantum efficiency for the twisted form of $\mathbf{3}$ is comparable to or slightly larger than that for its planar form. This in turn indicates that the twisted form has a lower fluorescence decay rate constant than the planar form, since the former has a longer lifetime. Shorter lifetimes observed for the planar forms of PPEs have been attributed to a smaller difference in molecular geometry between the ground and the excited states. ${ }^{17,33}$ According to the Franck-Condon principle, a larger value of $I_{01} / I_{00}$ for the twisted form also indicates a larger displacement of nuclear coordinates on going from the ground to the excited states. ${ }^{35} \mathrm{It}$ should be noted that the $0-0$ fluorescence band $(346 \mathrm{~nm})$ of the twisted form is at shorter wavelength than the $0-0$ absorption band (354 nm). Apparently, the 354-nm absorption band is exclusively from the planar form. Along this line, the fraction of the planar form at $80 \mathrm{~K}$ is still significant, and the negligible fluorescence from the planar form at $80 \mathrm{~K}$ upon excitation at $302 \mathrm{~nm}$ is simply due to its weak absorption at $302 \mathrm{~nm}$. Likewise, the negligible fluorescence from the twisted form at $320 \mathrm{~K}$ indicates fast excited-state structural relaxation to the planar form. Therefore, lowering the temperature not only increases the population of the twisted form but also reduces the thermal relaxation of the twisted form to the planar form. The absence of excited-state conformer equilibration was previously found for many trans-1,2-diarylethenes ${ }^{36}$ but not for DPA or its $\pi$-elongated PPEs.

In the case of tetramer 4 , the electronic spectra are red-shifted relative to those of $\mathbf{3}$ due to its longer conjugation length (Table 1). The solvent dependence of the absorption spectra for 4 resembles the case of $\mathbf{3}$ (Figure S1), where the spectra undergo blue shifts in more polar solvents. Both of the values of fluorescence quantum yield for $\mathbf{4}$ in chloroform or MTHF are slightly higher than those for $\mathbf{3}$, consistent with the longer fluorescence lifetimes. However, the temperature effect on fluorescence is more significant for 4. As shown in Figure 6, the fluorescence spectra are blue-shifted by as large as $41 \mathrm{~nm}$ from 320 to $80 \mathrm{~K}$, and the location of the $0-0$ fluorescence band $(346 \mathrm{~nm})$ at $80 \mathrm{~K}$ is the same as that for the twisted form of $\mathbf{3}$.

(35) (a) Bässler, H.; Schweitzer, B. Acc. Chem. Res. 1999, 32, 173-182. (b) Liu, Y.; Jiang, S.; Glusac, K.; Powell, D. H.; Anderson, D. F.; Schanze, K. S. J. Am. Chem. Soc. 2002, 124, 12412-12413.

(36) (a) Mazzucato, U.; Momicchioli, F. Chem. Rev. 1991, 91, 1679-1719. (b) Saltiel, J.; Choi, J.-O.; Sears, D. F., Jr.; Eaker, D. W.; Mallory, F. B.; Mallory, C. W. J. Phys. Chem. 1994, 98, 13162-13170. (c) Lewis, F. D.; Yoon, B. A.; Arai, T.; Iwasaki, T.; Tokumaru, K. J. Am. Chem. Soc. 1995 , 117, 3029-3036.
Table 1. Photophysical Data of Compounds $2-5$ in Chloroform $\left(\mathrm{CHCl}_{3}\right)$, 2-Methyltetrahydrofuran (MTHF), and Spin-Cast Film at Room Temperature (ca. $296 \mathrm{~K}$ )

\begin{tabular}{|c|c|c|c|c|c|c|}
\hline compd & media $^{a}$ & $\lambda_{\mathrm{abs}}(\mathrm{nm})^{b}$ & $\lambda_{\mathrm{fl}}(\mathrm{nm})^{b}$ & $I_{01} / I_{00^{c}}$ & $\Phi_{\mathrm{fl}}$ & $\tau_{\sharp \|}(\mathrm{ns})\left(\lambda_{\mathrm{ex}}, \lambda_{\mathrm{em}}\right)$ \\
\hline \multirow[t]{3}{*}{2} & $\mathrm{CHCl}_{3}$ & $298(316)$ & $328(341)$ & 0.79 & 0.40 & $0.92(296,328)$ \\
\hline & MTHF & $297(315)$ & $327(342)$ & 0.81 & 0.38 & $1.12(296,328)$ \\
\hline & film & $301(319)$ & $335(350)$ & 1.05 & & \\
\hline \multirow[t]{3}{*}{3} & $\mathrm{CHCl}_{3}$ & $334(354)$ & $368(388)$ & 0.65 & 0.60 & $0.60(337,373)$ \\
\hline & MTHF & $334(354)$ & 366 (387) & 0.67 & 0.63 & $0.65(337,363)$ \\
\hline & film & $336(356)$ & 374 (392) & 0.91 & 0.20 & \\
\hline \multirow[t]{3}{*}{4} & $\mathrm{CHCl}_{3}$ & $340(370)$ & 389 (412) & 0.65 & 0.69 & $0.67(354,392)$ \\
\hline & MTHF & 341 (367) & 387 (410) & 0.66 & 0.71 & $0.68(337,412)$ \\
\hline & film & 349 (374) & $393(415)$ & 1.15 & 0.20 & \\
\hline \multirow[t]{3}{*}{5} & $\mathrm{CHCl}_{3}$ & 335 & 367 (387) & 0.59 & 0.71 & $0.78(337,373)$ \\
\hline & MTHF & $334(353)$ & $365(385)$ & 0.62 & 0.77 & $0.74(337,373)$ \\
\hline & film & 349,377 & $387,414,442$ & & 0.18 & \\
\hline
\end{tabular}

${ }^{a}$ Films are prepared by spin casting. ${ }^{b}$ The second vibronic band is given in parentheses. ${ }^{c}$ Intensity ratio of the 0,1 vs the 0,0 fluorescence band.

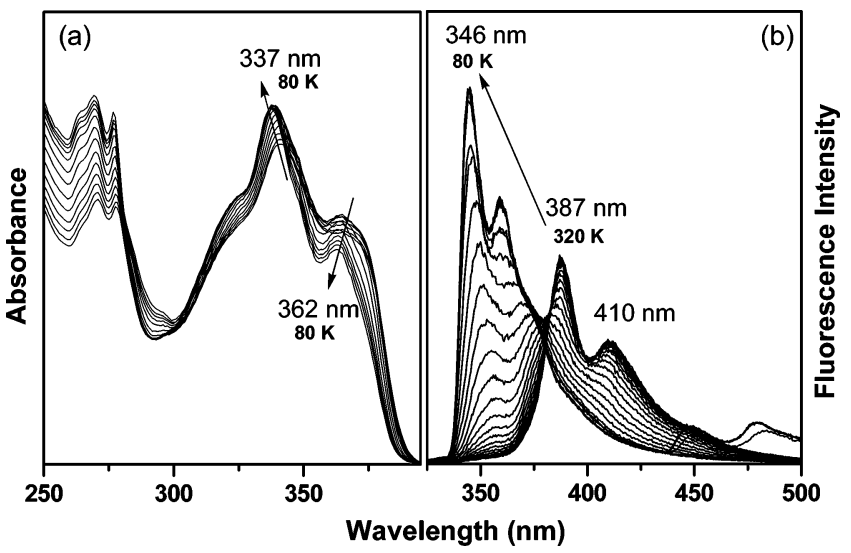

Figure 6. Temperature dependence of (a) absorption and (b) fluorescence spectra $\left(\lambda_{\mathrm{ex}}=303 \mathrm{~nm}\right)$ of $\mathbf{4}$ in MTHF at 20- and 10-K intervals, respectively, between 80 and $320 \mathrm{~K}$.

There is also an isosbestic point $(380 \mathrm{~nm})$ for the fluorescence spectra of $\mathbf{4}$ as a function of temperature. The corresponding fluorescence decays are monoexponential at room temperature (0.68 ns) but become nonexponential at temperature lower than $280 \mathrm{~K}$. The fluorescence decays at temperatures lower than 160 $\mathrm{K}$ can be fit by biexponential functions, corresponding to lifetimes of 0.8 and $5.5 \mathrm{~ns}$, and the component of longer lifetime (5.5 ns) is dominant ( $>60 \%)$. By following the same arguments for the case of $\mathbf{3}$, the $\pi$-conjugated backbone of $\mathbf{4}$ becomes more twisted at lower temperatures. The more complex fluorescence decay behavior for $\mathbf{4}$ vs $\mathbf{3}$ can be attributed to the presence of one more pentiptycene group so that the ground-state rotational energy profile becomes more complex. It is interesting to note that the fluorescence quantum yield for the twisted form of $\mathbf{4}$ approaches unity at $80 \mathrm{~K}$, provided that both the planar form and the twisted form have no activated nonradiative decay pathways. In addition, despite the longer conjugation length for 4 vs 3 , both the fluorescence position and the fluorescence lifetimes are nearly the same for the twisted forms of $\mathbf{3}$ and $\mathbf{4}$. Assuming that the twisted forms for $\mathbf{3}$ and $\mathbf{4}$ are zipperlike structures (Figure 7), this appears to indicate that the additional terminal ring in the four-ring zipper has little electronic interactions with the rest of the backbone (i.e., the three-ring zipper). The blue-shifted electronic spectra and the increased fluorescence quantum yields for the twisted vs the planar form for $\mathbf{3}$ and $\mathbf{4}$ are consistent with the observations for the Swager's 


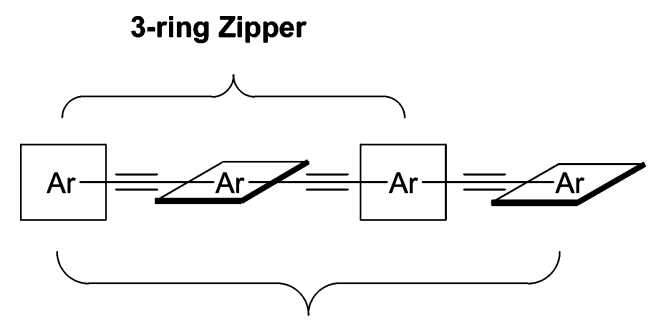

4-ring Zipper

Figure 7. Schematic drawings for the structure of three-ring and four-ring Zipper.

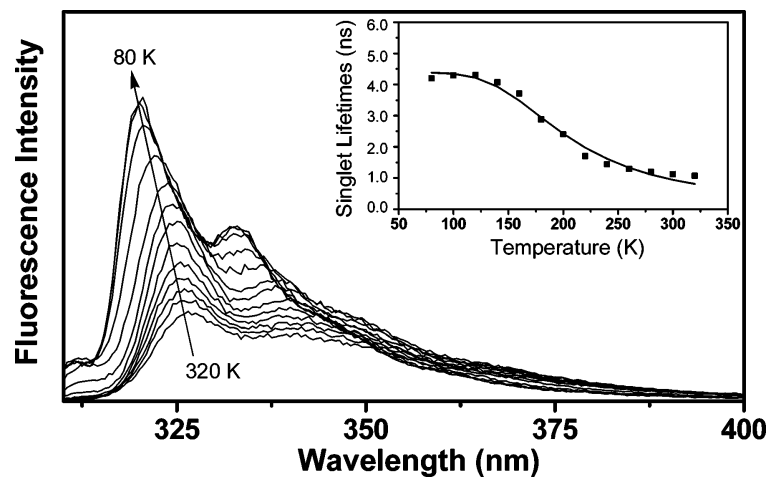

Figure 8. Fluorescence spectra of $\mathbf{2}$ in MTHF at 20-K intervals between 80 and $320 \mathrm{~K}\left(\lambda_{\mathrm{ex}}=306 \mathrm{~nm}\right)$. Inset shows the temperature-dependent fluorescence lifetimes and nonlinear fits to eq 2 .

PPEs in Langmuir-Blodgett films, ${ }^{18}$ although interchain effects might not be negligible in these LB films (vide supra).

When compared with $\mathbf{3}$ and $\mathbf{4}$, the dimer $\mathbf{2}$ is as expected blue-shifted in their electronic spectra due to its shorter conjugation length (Table 1). The absorption spectra of 2 are also solvent-polarity-dependent in a way similar to that for $\mathbf{3}$, albeit to a much smaller degree (Figure S1). The inherent fluorescence quantum yield for $\mathbf{2}$ is lower than that for $\mathbf{3}$, which could be readily understood in terms of their fluorescing states. ${ }^{37-39}$ It is known that the fluorescence of DPA and most substituted DPAs in solutions is from the second excited state $\left(S_{2}\right)$ rather than the $S_{1} \cdot{ }^{37,38}$ As a result of efficient internal conversion from $S_{2}$ to $S_{1}$, the fluorescence quantum yields are generally low for DPAs (e.g., 0.004 for DPA). It should be noted that the $S_{2} \rightarrow S_{1}$ transition in DPA is an activated process. In other words, the fluorescence quantum yield will be temperaturedependent. Indeed, the fluorescence intensity of dimer $\mathbf{2}$ in MTHF increases as the temperature is decreased (Figure 8). In conjunction with the single-exponential fluorescence decays at all selected temperatures and the small blue shift of fluorescence $(\Delta \lambda=4 \mathrm{~nm})$ from 320 to $160 \mathrm{~K}$, these results indicate that the nature of the fluorescing states at all temperatures are similar and possess activated nonradiative decay processes. Assuming that the $S_{2} \rightarrow S_{1}$ transition was the only activated singlet-decay process of $\mathbf{2}$ and that its $k_{\mathrm{f}}$ was temperature-independent, the transition barrier can be obtained from a nonlinear fitting of

(37) (a) Hirata, Y. Bull. Chem. Soc. Jpn. 1999, 72, 1647-1664. (b) Zgierski, M. Z.; Lim, E. C. Chem. Phys. Lett. 2004, 387, 352-355.

(38) McFarland, S. A.; Finney, N. S. J. Am. Chem. Soc. 2002, 124, 11781179.

(39) Beeby, A.; Findlay, K. S.; Low, P. J.; Marder, T. B.; Matousek, P.; Parker, A. W.; Rutter, S. R.; Towrie, M. Chem. Commun. 2003, 2406-2407.

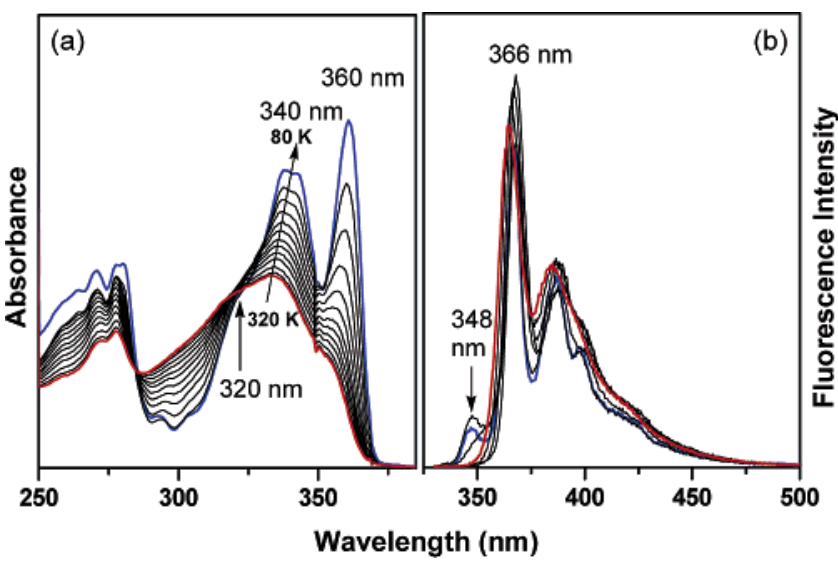

Figure 9. Temperature dependence of (a) absorption and (b) fluorescence spectra $\left(\lambda_{\mathrm{ex}}=320 \mathrm{~nm}\right)$ of $\mathbf{5}$ in MTHF at 20 - and $40-\mathrm{K}$ intervals, respectively, between 80 (blue) and $320 \mathrm{~K}$ (red).

the fluorescence lifetimes using eq $2: 40$

$$
\tau_{\mathrm{f}}(T)=1 /\left[\Sigma k+A \exp \left(-E_{\mathrm{a}} / R T\right)\right]
$$

where $\Sigma k$ is the sum of all nonactivated processes (fluorescence and intersystem crossing), and $A$ and $E_{\mathrm{a}}$ are the preexponential and activation energy for the activated process, respectively. The plot of $\tau_{\mathrm{f}}$ against temperature for $\mathbf{2}$ is shown in the inset of Figure 8 , and the derived activation energy for nonradiative decay is $630 \mathrm{~cm}^{-1}$, a value very similar to that for DPA $(610$ $\left.\mathrm{cm}^{-1}\right) \cdot{ }^{38}$ Therefore, the much higher fluorescence quantum yield for $\mathbf{2}$ vs DPA results from a decrease in the preexponential factor rather than from an increase in the activation energy. The above analysis could not exclude the possibility of the presence of a small amount of twisted conformers at low temperatures, regarding the appearance of a shoulder at the blue edge of the fluorescence spectra at low temperatures. The negligible contribution of these twisted conformers to the fluorescence decay analysis might suggest weak fluorescence and/or short fluorescence lifetimes for them. Bunz and co-workers have shown that twisting the backbone of DPA results in low fluorescence quantum yields. ${ }^{20}$

The electronic transition energy for $\mathbf{5}$ is similar to that for $\mathbf{3}$ (Table 1), but its spectral behavior differs from $\mathbf{3}$ in several aspects: (1) the absorption spectra for $\mathbf{5}$ in solutions are less structured in all selected solvents, and the red edge of the spectra grows in at the expense of the intensity of the blue shoulder of the absorption band upon increasing the solvent polarity (Figure S1). (2) The absorption spectra for $\mathbf{5}$ in MTHF undergo red shifts with a sharp band at $360 \mathrm{~nm}$ growing in upon lowering the temperature (Figure 9a). (3) As the solvent polarity is increased, the red shifts and spectral broadening in both the absorption and fluorescence spectra are larger for 5 (e.g., a shift of $12 \mathrm{vs} 7 \mathrm{~nm}$ in fluorescence and a fluorescence band halfwidth of 100 vs $65 \mathrm{~nm}$ in acetonitrile) (Figure S1). (4) The fluorescence $I_{01} / I_{00}$ values and quantum yields for $\mathbf{5}$ are lower and larger, respectively, in both $\mathrm{CHCl}_{3}$ and MTHF (Table 1). (5) Except for a sharpening of the vibronic bands at low temperatures, the fluorescence spectra for $\mathbf{5}$ in MTHF display little dependence on temperature (Figure $9 \mathrm{~b}$ ). The $0-0$ band

(40) (a) Lewis, F. D.; Zuo, X. J. Am. Chem. Soc. 2003, 125, 2046-2047. (b) Lewis, F. D.; Zuo, X. J. Am. Chem. Soc. 2003, 125, 8806-8813. (c) Yang,

J.-S.; Liau, K.-L.; Hwang, C.-Y.; Wang, C.-M. J. Phys. Chem. A 2006, $110,8003-8010$. 


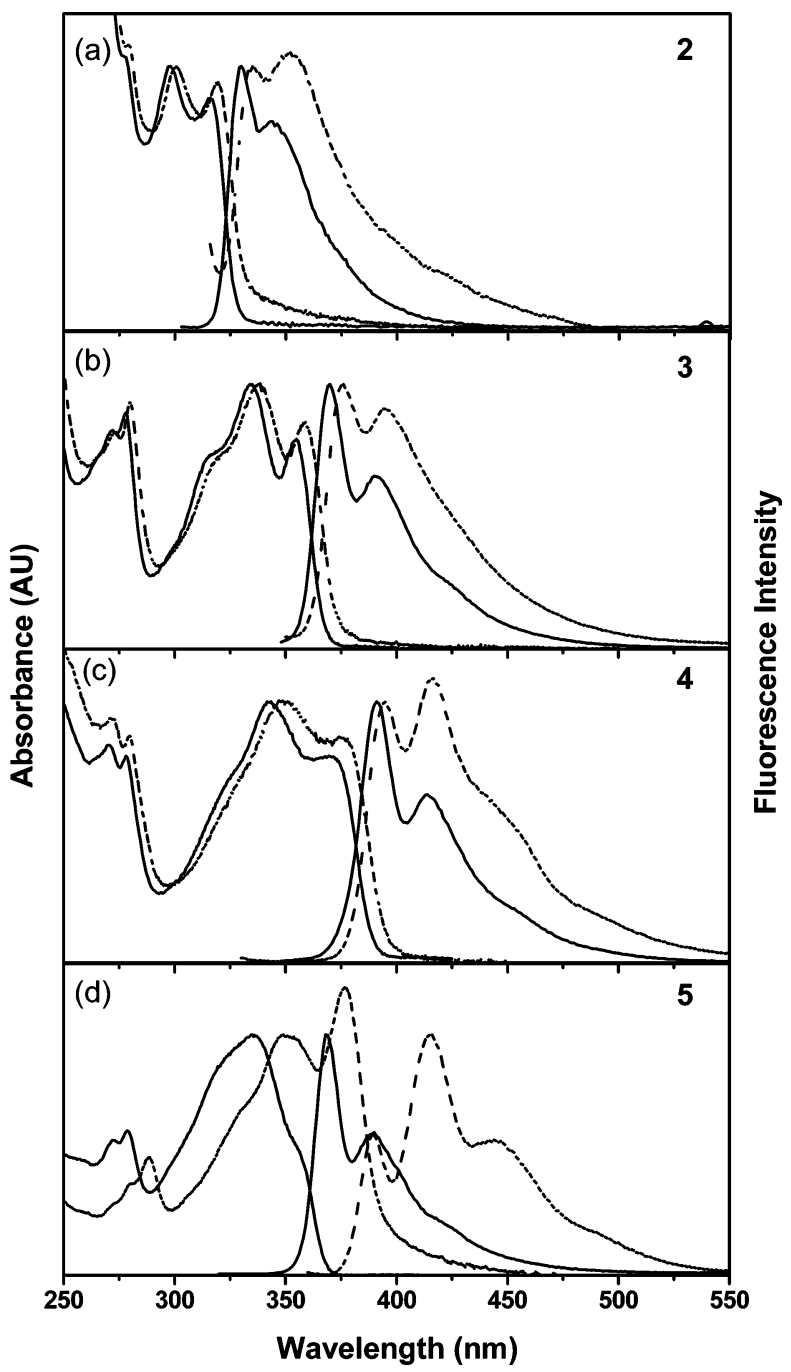

Figure 10. Normalized absorption and fluorescence spectra of (a) 2, (b) 3, (c) 4, and (d) $\mathbf{5}$ in chloroform (solid) and spin-cast films (dash).

undergoes a small red shift $(\Delta \lambda=3 \mathrm{~nm})$ upon decreasing the temperature from 320 to $80 \mathrm{~K}$, resembling the case of $1 .^{16,17} \mathrm{~A}$ small peak at $348 \mathrm{~nm}$ grows in at temperatures lower than 160 $\mathrm{K}$, which might result from a small amount of twisted conformers. (6) No phosphorescence is observed for 5 in lowtemperature glasses. All these observations indicate that $\mathbf{5}$ becomes more planar in more polar solvents or at lower temperatures, a behavior opposite to that for $\mathbf{3}$. Such a difference should be associated with their differences in rotational potential in both $\mathrm{S}_{0}$ and $\mathrm{S}_{1}$ (Figure 1).

In conjunction with the behavior of DPA and $\mathbf{1}$, our results for 2-5 clearly show that the intrachain pentiptycene-pentiptycene interactions in $\mathbf{2 - 4}$ play an important role in determining the ground-state and the excited-state rotational energy profiles, the distribution of conformers, and in turn their solvent- and temperature-dependent photophysical properties. However, regarding the symmetric molecular structures and nonpolar nature of $\mathbf{3}$ and 4, the origin of the intriguing solvent and temperature effects on their conformer distribution remains to be investigated.

Interchain Effects. The influence of interchain interactions on the photophysical properties of $\mathbf{2 - 5}$ was investigated for samples in thin solid films. The films of optical densities in the range of 0.1 and 0.2 at the absorption maxima were prepared

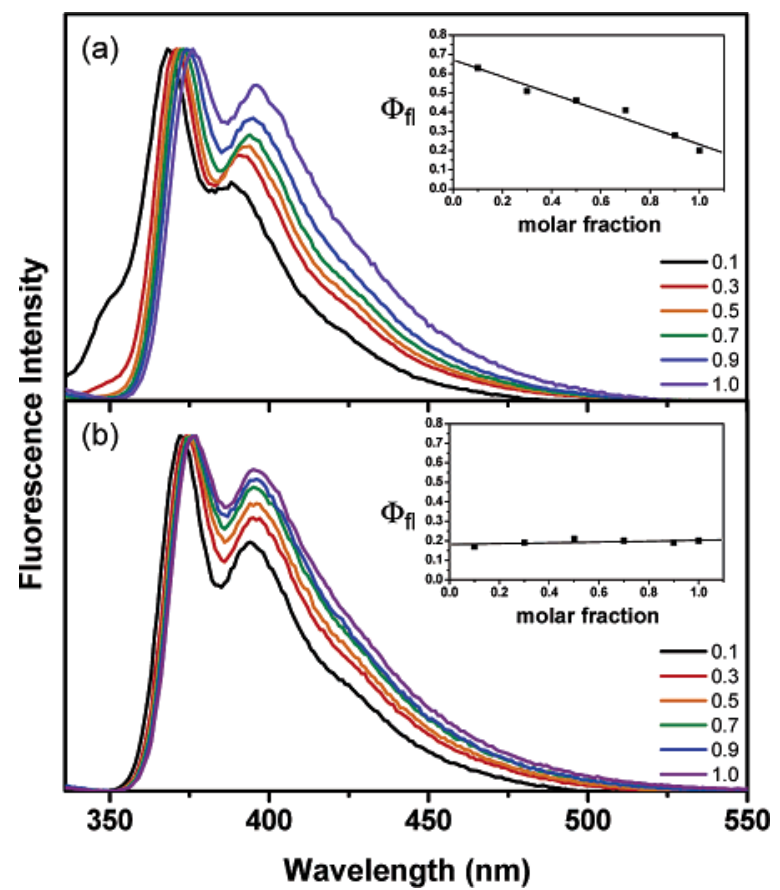

Figure 11. Normalized fluorescence spectra for films of $\mathbf{3}$ mixed with (a) PMMA and with (b) 2 at different molar fractions $(3=0.1,0.3,0.5,0.7$, 0.9 , and 1.0). Insets show the corresponding changes in fluorescence quantum yields.

by spin casting with $5 \times 10^{-3} \mathrm{M}$ chloroform solutions. Because of the poorer film quality for $\mathbf{2}$ that causes larger light scattering, our discussion will mainly rely on the behavior of $\mathbf{3}-\mathbf{5}$.

As shown in Figure 10, transformations of $\mathbf{2 - 4}$ from dilute solutions to spin-cast thin films result in small red shifts $(\Delta \lambda=$ 2-9 $\mathrm{nm}$ ) in both the absorption and fluorescence spectra. In contrast, not only large spectral shifts $(14-21 \mathrm{~nm})$ but also a new sharp absorption band at $377 \mathrm{~nm}$ is observed in the case of 5. The above differences between $\mathbf{2 - 4}$ and $\mathbf{5}$ can be readily understood based on their molecular and crystal structures (vide supra), where interchain $\pi$-stacking interactions are possible only in 5. On the basis of the crystal packing mode (Figure 3) and the structured fluorescence spectra, the new absorption band at $377 \mathrm{~nm}$ for $\mathbf{5}$ can be attributed to the formation of $J$-type aggregates. ${ }^{41}$

Despite the small spectral shifts for $\mathbf{2 - 4}$ in thin films vs dilute solutions, the ratio of $I_{01} / I_{00}$ in the fluorescence spectra is markedly increased, particularly for the case of $\mathbf{4}$ (Figure 10 and Table 1). This phenomenon can be interpreted by the reabsorption effect in optically dense conditions, ${ }^{42,43}$ which is more significant on the $0-0$ than the $0-1$ bands. Indeed, the solution-like $I_{01} / I_{00}$ ratio can be recovered when the sample is diluted with inert solid matrixes such as poly(methyl methacrylate) (PMMA). Typical spectra represented by $\mathbf{3}$ are shown in Figure 11a. In addition, the reabsorption effect on fluorescence could be simulated, to a first approximation, using eq $3:^{42}$

$$
F^{\prime}(v)=F(v)\left[10^{-\epsilon(v) k}\right]
$$

where $F(v)$ is the solution fluorescence spectrum, $F^{\prime}(v)$ is the

(41) Siddiqui, S.; Spano, F. C. Chem. Phys. Lett. 1999, 38, 99-105.

(42) Dhami, S.; De Mello, A. J.; Rumbles, G.; Bishop, S. M.; Phillips, D.; Beeby, A. Photochem. Photobiol. 1995, 61, 341-346.

(43) (a) Dutta, A. K. Langmuir 1996, 12, 5909-5914. (b) Dutta, A. K. J. Phys. Chem. B 1997, 101, 569-575. 


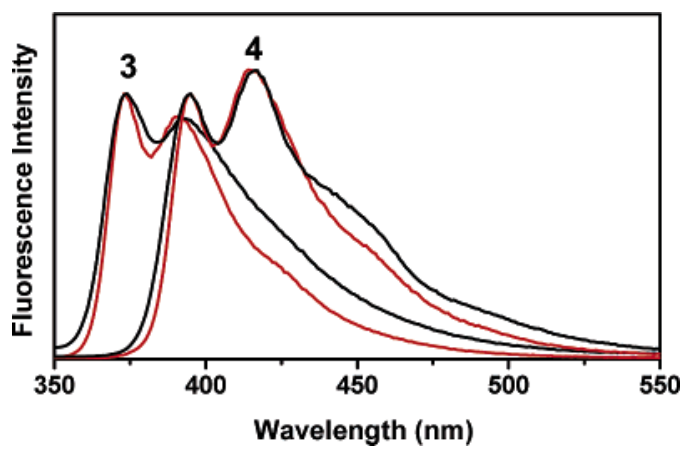

Figure 12. Comparison of the simulated fluorescence spectrum using eq 3 (red) and the observed thin-film fluorescence spectra (black) for $\mathbf{3}$ and $\mathbf{4}$

distorted fluorescence spectrum after reabsorption, $\epsilon(v)$ is the molar absorptivity of the thin-film absorption spectrum, and $k$ is a parameter proportional to the concentration of samples and the thickness through which the fluorescence photons have to escape. The values of $\epsilon(v)$ were derived from the molar absorptivity of solution spectra through spectra normalization (Figure 10). As shown in Figure 12, the simulated fluorescence spectra after reabsorption for $\mathbf{3}$ and $\mathbf{4}$ agree well with the observed thin-film spectra. The somewhat broader spectra for them in thin films vs in solutions can be attributed to the broader conformer distribution in the excited states. A larger reabsorption effect for $\mathbf{4}$ vs $\mathbf{3}$ could be accounted for by the larger molar absorptivity, which is $1.10 \times 10^{5}$ and $6.93 \times 10^{4} \mathrm{~L} \mathrm{~mol}^{-1} \mathrm{~cm}^{-1}$ in chloroform, respectively. It should be noted that even though reabsorption is the major effect in accounting for the spectral differences for films vs solutions, the role of interchain interactions cannot be neglected (vide infra). In contrast, the treatment of eq 3 cannot regenerate the thin-film fluorescence spectra for 5. Thus, we conclude that the thin-film fluorescence for $\mathbf{2} \mathbf{- 4}$ is mainly of intrachain or molecular nature, but for $\mathbf{5}$ it is mainly from the $J$-aggregates.

Upon correction for the reabsorption effect, the fluorescence spectra of $\mathbf{2 - 4}$ in thin solid films would be similar to the roomtemperature solution spectra. This in turn suggests that the emitting species in thin films is mainly the planar form of molecules. The absence of emission from the twisted form can be attributed to efficient exciton migration from the excited twisted form to the planar form in thin films. Evidence of efficient exciton migration in the films of $\mathbf{2 - 4}$ is further provided by films that contain two or all three compounds of $\mathbf{2}-\mathbf{4}$, where $\mathbf{2}$ or $\mathbf{3}$ is the energy donor and $\mathbf{3}$ or $\mathbf{4}$ is the energy acceptor. Our preliminary studies indicate that when the molar fraction of the acceptor is larger than 0.1, the observed fluorescence of these bi- or tri-component films is almost entirely from the acceptor upon excitation at the absorption maxima of the donor. A typical example provided by the $\mathbf{2}$ and 3 mixed films is shown in Figure 11b. The larger dependence of the fluorescence spectra on molar fractions for $\mathbf{3}$ in PMMA than in $\mathbf{2}$ and the presence of a shoulder in the blue edge of the fluorescence spectra for $\mathbf{3}$ in PMMA at lower molar fractions (e.g., at 0.1 , Figure 11) clearly suggest that the efficiency of exciton migration from the twisted to the planar forms is reduced when $\mathbf{3}$ is dispersed in PMMA but not in $\mathbf{2}$ (see below for further discussion).

Although the reabsorption effect is responsible for the changes in $I_{01} / I_{00}$ for $\mathbf{2}-\mathbf{4}$, it alone does not account for the significant decrease in the fluorescence quantum yields for $\mathbf{3}$ and $\mathbf{4}$ on going from $0.6-0.69$ in chloroform to 0.20 in spin-cast films (Table $1)$. This is manifested by comparing the values of $\Phi_{\mathrm{fl}}$ for them with different molar fractions in PMMA and in 2. As shown in Figure 11, the concentration dependence of the $I_{01} / I_{00}$ value for 3 mixed with 2 is similar to that with PMMA. However, the corresponding changes in $\Phi_{\mathrm{fl}}$ are very different. Whereas the values of $\Phi_{\mathrm{fl}}$ increase as the molar fraction of $\mathbf{3}$ in PMMA decreases (i.e., upon dilution of $\mathbf{3}$ ) and reaches a value similar to that in solution (i.e., 0.63) at a molar fraction of 0.1 , the values of $\Phi_{\mathrm{fl}}$ are relatively lower and insensitive to the molar ratio of $\mathbf{3}$ when the PMMA is replaced by $\mathbf{2}$ (Figure 11b, inset). Since the presence of a small amount of external fluorescence quenchers generally dictates the observed fluorescence quantum yield for systems in condensed phases when interchain exciton migration is present, ${ }^{6,19}$ the larger fluorescence quenching effects observed for the $\mathbf{2}-\mathbf{3}$ vs the PMMA-3 mixed films might reflect more population of the nonfluorescent energy traps and more efficient exciton migration to nonfluorescent energy traps in the former films. Because of the bulky iptycene substituents in $\mathbf{2 - 4}$, the nonfluorescent energy traps should not be attributed to the conventional interchain $\pi$-stacked excimers. ${ }^{44}$ On the basis of the dipole-dipole model, cofacial alignment of molecules in a high-symmetry configuration (e.g., $H$-type aggregates) is known to be detrimental to the fluorescence efficiency, because the lowest excited state is not optically coupled to the ground state. ${ }^{1,45}$ Thus, nonfluorescent traps created by the $H$-type dipole-dipole interactions for $\mathbf{2 - 4}$ in the crystalline domains of thin films is not unexpected in view of the expected parallel interchain packings. A parallel interchain alignment can also facilitate exciton migration through the Förster mechanism ${ }^{46}$ to the traps or impurities. Therefore, we conclude that the low fluorescence quantum yields for $\mathbf{2 - 4}$ in thin films is a consequence of parallel interchain packing that favors dipoledipole-induced interchain exciton migration to the nonemissive traps that are either $H$-aggregates or impurities. Along this line, the more efficient exciton migration in the $\mathbf{2}-\mathbf{3}$ than the PMMA $\mathbf{- 3}$ films might reflect a more parallel arrangement for 3 in the former films (Figure 11). This argument is supported when comparing the thin-film fluorescence of $\mathbf{2}-\mathbf{4}$ with that of polymer $18(\mathrm{Mn}=144000) .{ }^{26 \mathrm{~b}}$ The morphology of 18 in thin films is expected to be more amorphous due to the longer conjugated backbones and the presence of long alkoxy side chains. Thus, the change in $I_{01} / I_{00}$ and $\Phi_{\mathrm{fl}}$ for $\mathbf{1 8}$ on going from dilute chloroform solutions $\left(I_{01} / I_{00}=0.26\right.$ and $\left.\Phi_{\mathrm{fl}}=0.50\right)$ to thin solid films $\left(I_{01} / I_{00}=0.28\right.$ and $\left.\Phi_{\mathrm{fl}}=0.33\right)$ is much smaller than that for $\mathbf{2 - 4}$.

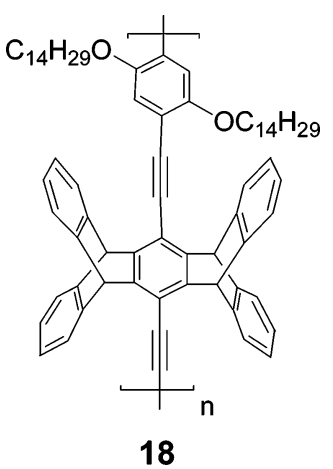

Despite the presence of strong interchain $\pi$-stacking interactions, the fluorescence quantum yield for $\mathbf{5}$ is similar to that 
for the bulky analogue $\mathbf{3}$ in the solid state. This can be attributed to the allowed $\mathrm{S}_{1} \rightarrow \mathrm{S}_{0}$ optical transition for $J$-aggregates, which dictate the fluorescence behavior of $\mathbf{5}$ in thin films.

\section{Experimental Section}

Materials. THF and MTHF were dried by sodium metal and distilled before use. All the other solvents for spectra and quantum yield measurements were HPLC grade and used as received. Compounds $\mathbf{6},{ }^{26} \mathbf{8},{ }^{26} \mathbf{1 7},{ }^{28}$ and 1-iodo-4-octyloxybenzene ${ }^{47}$ were prepared according to the literature procedures. Detailed synthetic procedures and structural characterization data for compounds $\mathbf{2 - 5}$ and $\mathbf{9 - 1 6}$ are provided as Supporting Information.

Methods. Electronic spectra were recorded at room temperature (23 $\pm 1{ }^{\circ} \mathrm{C}$ ). UV-visible spectra were measured on a Cary 300 double beam spectrophotometer. Fluorescence spectra were recorded on an Edinburgh FLS920 or a PTI QuantaMaster C-60 spectrometer and corrected for the response of the detector. The optical density (OD) of all solutions and thin films was about 0.1 at the wavelength of excitation. The fluorescence spectra at other temperature were measured in an Oxford OptistatDN cryostat with an ITC502 temperature controller. A $\mathrm{N}_{2-}$ bubbled solution of anthracene $\left(\Phi_{\mathrm{f}}=0.27 \text { in hexane }\right)^{48}$ or phenanthrene $\left(\Phi_{\mathrm{f}}=0.13 \text { in cyclohexane }\right)^{49}$ was used as a standard for the fluorescence quantum yield determinations of compounds $\mathbf{2}-\mathbf{5}$ under $\mathrm{N}_{2}$-bubbled chloroform solutions with solvent refractive index correction. An error of $\pm 10 \%$ is estimated for the fluorescence quantum yields. Fluorescence quantum yields in thin solid films $(\mathrm{OD} \approx 0.1-0.2)$ were determined relative to equiabsorbing films of 9,10 -diphenylanthracene in poly(methyl methacrylate) $(\mathrm{PMMA})\left(\Phi_{\mathrm{f}}=0.83\right) .^{50}$ Fluorescence decays were also measured at room temperature by the Edinburgh FLS920 spectrometer with a gated hydrogen or nitrogen arc lamp using a scatter solution to profile the instrument response function. The goodness of the nonlinear least-squares fit was judged by the reduced $\chi^{2}$ value $(<1.2$ in all cases), the randomness of the residuals, and the autocorrelation function. The X-ray crystal structures were determined with a Siemens SMART CCD diffractometer with graphite-monochromated Mo K $\alpha$ radiation $(\lambda=0.71073 \AA)$ at $150 \pm 1 \mathrm{~K}$. AM1 and ZINDO calculations were performed on a PC cluster using the algorithms supplied with the package of Gaussian 03 revision B.02, a product of Gaussian Inc. ${ }^{51}$

\section{Concluding Remarks}

Our systematic studies on $\mathbf{2} \mathbf{- 5}$ have provided important insights into the intrachain conformation and interchain exciton coupling effects on the fluorescence properties of PPEs. Because of the unique iptycene substituent effects in $\mathbf{3}$ and $\mathbf{4}$, a local energy minimum is present in the twisted region of their rotational potentials in $S_{0}$ and $S_{1}$, and the distribution of rotational conformers is sensitive to the solvent polarity and temperature, where the twisted conformers become more

(44) (a) Nontraditional excimers were recently reported by Swager and coworkers for PPEs with specific [2.2.2] bicyclic ring substituents. ${ }^{42 \mathrm{~b}}$ (b) Kim, Y.; Bouffard, J.; Kooi, S. E.; Swager, T. M. J. Am. Chem. Soc. 2005, 127, $13726-13731$.

(45) (a) Maillou, T.; Le Moigne, J.; Dumarcher, V.; Rocha, L.; Geffroy, B.; Nunzi, J.-M. Adv. Mater. 2002, 14, 1297-1301. (b) He, F.; Xu, H.; Yang, B.; Duan, Y.; Tian, L.; Huang, K.; Ma, Y.; Liu, S.; Feng, S.; Shen, J. Adv. Mater. 2005, 17, 2710-2714.

(46) Turro, N. J. In Modern Molecular Photochemistry; University Science Books: Sausalito, CA, 1991; Chapter 9

(47) Chang, J. Y.; Baik, J. H.; Lee, C. B.; Han, M. J. J. Am. Chem. Soc. 1997 119, 3197-3198.

(48) Dawson, W. R.; Windsor, M. W. J. Phys. Chem 1968, 72, 3251-3260.

(49) Berlman, I. B. Handbook of Fluorescence Spectra of Aromatic Molecules, 2nd ed.; Academic Press: New York, 1971

(50) Osaheni, J. A.; Jenekhe, S. A. J. Am. Chem. Soc. 1995, 117, 7389-7398.

(51) Frisch, M. J. et al. Gaussian 03, revision B.03; Gaussian, Inc.; Pittsburgh, PA, 2003; full reference given in the Supporting Information.

(52) (a) Chandrasekharan, N.; Kelly, L. A. J. Am. Chem. Soc. 2001, 123, $9898-$ 9899. (b) Padmanaban, G.; Ramakrishnan, S. J. Phys. Chem. B 2004, 108 14933-14941. (c) Kwak, G.; Fukao, S.; Fujiki, M.; Sakaguchi, T.; Masuda, T. Chem. Mater. 2006, 18, 2081-2085.

(53) (a) Zahn, S.; Swager, T. M. Angew. Chem., Int. Ed. 2002, 41, 4226-4230. (b) Xie, Z.; Yang, B.; Li, F.; Cheng, G.; Liu, L.; Yang, G.; Xu, H.; Ye, L.; Hanif, M.; Liu, S.; Ma, D.; Ma, Y. J. Am. Chem. Soc. 2005, 127, 1415214153 . favorable in more polar solvents and at lower temperatures. More importantly, for $\mathbf{3}$ and $\mathbf{4}$ in MTHF the excited-state conformational relaxation from the twisted form to the planar form is inhibited at low temperatures, which allows us to characterize the photophysics of the twisted conformers. Backbone twisting for $\mathbf{3}$ and $\mathbf{4}$ leads to blue-shifted absorption and fluorescence spectra, longer fluorescence lifetimes, and larger fluorescence quantum yields. The large fluorescence spectral shifts for $\mathbf{4}$ as a function of temperature is reminiscent of the recent efforts toward the development of fluorescent thermosensors. ${ }^{52}$ The fluorescence behavior of $\mathbf{2}$ is different from that of 3 and 4, which can be attributed to the different electronic structures ( $S_{2}$ vs $S_{1}$ emission) and/or weaker intrachain pentiptycene-pentiptycene interactions. The intrachain fluorescence for 2-4 in dilute solutions is retained in thin solid films as a result of the bulky iptycene substituents that prevent interchain charge-transfer interactions. The reabsorption effect accounts for the increased intensity ratio for the $0-1$ vs the $0-0$ vibrational band. The significant reduction in fluorescence quantum yields for $\mathbf{3}$ and $\mathbf{4}$ in films vs solutions is however attributed to efficient interchain exciton migration to nonfluorescent energy traps. Unlike the "all-pentiptycene" analogue 3, the phenylene-pentiptycene-phenylene system $\mathbf{5}$ in MTHF displays different fluorescence responses to temperature and solvent polarity. In addition, interchain $\pi$-stacking through the terminal phenylene rings leads to the formation of $J$-type aggregates instead of excimers for $\mathbf{5}$ in thin solid films. While the differences between $\mathbf{3}$ and $\mathbf{5}$ reflect the intriguing iptycene substituent effects, $\mathbf{3}$ and $\mathbf{5}$ have similar fluorescence quantum yields in thin films, revealing that not only prevention of interchain $\pi$-stacking but also minimization of interchain dipole-dipole interactions are important to achieve high solidstate fluorescence efficiency. This recalls recent examples of strongly fluorescent films created by oblique orientation of neighboring transition dipoles. ${ }^{53}$ It is also interesting to point out that the size of red shifts in fluorescence spectra caused by the intrachain planarization effect, as deduced from $\mathbf{3}$, is nearly the same (ca. $1600 \mathrm{~cm}^{-1}$ ) as that by the interchain $J$-aggregation effect, as deduced from 5, for three-ring PE systems. There are at least two important aspects that remain to be investigated further. First, the origin of the iptycene substituent effects in $\mathbf{3}$ and 4 that lead to large conformational responses to solvents and temperature is unclear at present. Second, preliminary information about the chain-length effects on the difference in fluorescence behavior between the twisted and the planar form is provided by the comparison of $\mathbf{3}$ and $\mathbf{4}$, but the corresponding information for PE systems with longer chain lengths is unknown. Continued efforts toward a better understanding of these issues are in progress.

Acknowledgment. We thank the National Science Council of Taiwan, Academia Sinica, and UST for financial support and the National Center for High-performance Computing (Taiwan) for facilities.

Supporting Information Available: Detailed synthetic procedures and product characterization data, crystal refinement data, AM1 and ZINDO-derived rotational energies, solventdependent absorption and fluorescence spectra, and complete ref 51 (PDF) and X-ray experimental details (CIF). This material is available free of charge via the Internet at http://pubs.acs.org.

JA0640389 